Canadian

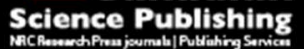

Canadian Journal of Civil Engineering Revue canadienne de génie civil

\title{
Field and Laboratory Permeability of Asphalt Concrete Pavements
}

\begin{tabular}{|r|l|}
\hline Journal: & Canadian Journal of Civil Engineering \\
\hline Manuscript ID & cjce-2016-0143.R1 \\
\hline Manuscript Type: & Article \\
\hline Date Submitted by the Author: & 07-Nov-2016 \\
\hline Complete List of Authors: & $\begin{array}{l}\text { Awadalla, Moustafa; IRC Building Sciences Group Inc. } \\
\text { Abd El Halim, Abd El Halim; Carleton University, Department of Civil and } \\
\text { Environmental Engineering } \\
\text { Hassan, Yasser; Carleton University, Department of Civil and } \\
\text { Environmental Engineering } \\
\text { Bashir, Imran ; Government of Ontario Ministry of Transportation } \\
\text { Pinder, Frank; Government of Ontario Ministry of Transportation Eastern } \\
\text { Region }\end{array}$ \\
\hline Keyword: & $\begin{array}{l}\text { Field and Laboratory Permeability, Asphalt Pavement, Moisture-Induced } \\
\text { Damage, Relative Density, Indirect Tensile Strength }\end{array}$ \\
\hline
\end{tabular}

SCHOLARONE $^{\text {m }}$

Manuscripts 


\section{Field and Laboratory Permeability of Asphalt Concrete Pavements}

Corresponding Author:

\section{Moustafa Awadalla}

Project Manager

IRC Building Sciences Group Inc.

2121 Argentia Road, Mississauga, Ontario, Canada, L5N 2X4

Tel: (905) 607-7244 Ext. 1211

E-mail: mawadalla@ircgroup.com

\section{A. O. Abd EI Halim}

Professor

Department of Civil and Environmental Engineering, Carleton University

1125 Colonel By Drive, Ottawa, Ontario, Canada, K1S 5B6

Tel: (613) 520-2600 x 5789

E-mail: abdel.halim@,carleton.ca

Yasser Hassan

Professor

Department of Civil and Environmental Engineering, Carleton University

1125 Colonel By Drive, Ottawa, Ontario, Canada, K1S 5B6

Tel: (613) 520-2600 x 8625

E-mail: yasser.hassan@carleton.ca

\section{Imran Bashir}

Bituminous Engineer

Ministry of Transportation Ontario (MTO)

1201 Wilson Ave, Toronto, Ontario, Canada, M3M 1J8

Tel: (416) 235-3546

E-mail: imran.bashir@ontario.ca

\section{Frank Pinder}

Area Contracts Engineer - Eastern Region

Ministry of Transportation Ontario (MTO)

1355 John Counter Blvd, Kingston, Ontario, Canada, K7L 5A3

Tel: (613)-545-4610

E-mail: frank.pinder@ontario.ca

Word count:

\begin{tabular}{ll} 
Manuscript & 4,677 \\
Tables $(6 * 250)$ & 1,500 \\
Figures $(10 * 250)$ & 2,500 \\
\cline { 2 - 2 } Total & 8,677
\end{tabular}




\begin{abstract}
Hot mix asphalt (HMA) pavements that have been poorly designed, compacted and/or constructed have higher chances of experiencing moisture-related damage. This research evaluates the interrelationship between field/laboratory permeability and other mechanical and physical pavement characteristics. Eight sites in Eastern Ontario were selected for evaluating the pavement's field permeability and core extraction. Laboratory specimens of the same mixes studied in the field were prepared using the Superpave gyratory compactor (SGC). The relative density (RD), lab permeability, and indirect tensile strength (IDT) tests were for the fieldrecovered cores and SGC specimens. Permeability, RD, and IDT were found to be related such that as RD and/or IDT decreases, the permeability increases exponentially. The strength of these relationships varied for the three test settings (SGC, field-recovered cores, and field measurements). The coefficients of field permeability and laboratory permeability using fieldrecovered cores were statistically different, with a fair relationship between these two test settings.
\end{abstract}

Key words: Field Permeability, Laboratory Permeability, Hydraulic Conductivity, Asphalt Pavement, Moisture-Induced Damage, Relative Density, and Indirect Tensile Strength. 


\section{INTRODUCTION}

The Superior Performing Asphalt Pavements (Superpave ${ }^{\circledR}$ ) system was initiated in late 1980s by the Strategic Highway Research Program (SHRP) to provide engineers, technicians and highway jurisdictions with a robust philosophy and procedures for designing hot-mix asphalt (HMA) pavement. One of the fundamental objectives of the Superpave ${ }^{\circledR}$ system is to build high quality asphalt road pavements with maximum durability, and better long term performance under different environmental and traffic loading challenges over the pavement lifespan (Kennedy et al. 1994). However, despite more than 20 years since the Superpave ${ }^{\circledR}$ products have been adopted in the pavement industry, it is still common to observe various premature pavement failures that could be attributed to inadequate mixture design, poor quality construction materials, unsuitable compaction equipment, repeated traffic loads, and environmental effects. One of the most serious distresses leading to asphalt pavement failures is the phenomenon known as the moisture-induced damage, which is a distress that occurs due to the presence of water within the pavement system and results in destroying the bond within the asphalt mix (Howson et al. 2009; Caro et al. 2010).

The existence of trapped water within a pavement structure leads to negative consequences by shortening the road service life or increasing the pavement maintenance and rehabilitation costs. Asphalt pavements that have been poorly designed, compacted and/or constructed have higher chances of experiencing moisture-related damage which adversely affects the asphalt strength and durability. The possible results of the reported early distress problems are moisture-induced cohesive and adhesive damage, fatigue cracking, potholes resulting from freeze-thaw cycles and/or permanent deformation (Umiliaco and Benedetto 2013). These concerns have been well investigated by numerous researchers to quantify the adverse 
effects of different distress problems (Chen et al. 2004; Kim et al. 2004; Pang 2012). Moistureinduced damage can be prevented through controlling the amount of water infiltrating through the pavement structure, which depends on the pavement permeability. In fact, permeability was found to be a better indicator of pavement durability compared to relative density alone, the most widely used acceptance parameter in quantifying the HMA compaction (McLaughlin and Goetz 1955). This is because higher permeability is more closely related to moisture-induced damage, which is considered one of the main mechanisms causing stripping.

Previous studies have concluded that the most prominent factor that influences pavement permeability is the content of interconnected air voids (Zube 1962; Mallick et al. 2003; Brown et al. 2004). The air voids content and relative density are inversely related such that as the air voids content increases, the relative density decreases and vice versa. However, unlike the interconnected air voids, the isolated voids do not correlate with high permeability coefficient as there are no flow channels where the water can penetrate through as illustrated in Error! Reference source not found.a and Error! Reference source not found.b. Another significant factor that affects the permeability coefficient is surface cracks. An impermeable surface can be achieved if surface cracks are eliminated as shown in Error! Reference source not found.c and Error! Reference source not found.d. In other words, a pavement structure has the potential to be impervious if it does not have surface cracks even when having some air voids within it.

While Zube (1962) suggested that the dense-graded asphalt pavement experiences an excessively high permeability rates at air voids more than $8 \%$, or a relative density value less than $92 \%$ of the theoretical maximum density, others concluded that high permeability coefficient exists even when providing acceptable air voids content in the field ranging from 5\% to $7 \%$ (Brown et al. 2004). Studies showed that the as-built density for dense-graded asphalt 
mixtures should not be more than $97 \%$ and not less than $92 \%$ of the theoretical maximum density (Roberts et al. 1996). Very high as-built density, which is usually caused by improper mix proportions, contributes to rutting and shoving. Alternatively, low as-built density, which is the result of inadequate compaction, allows more water and air to infiltrate through the pavement structure. This excessive infiltration is considered a major contributing factor to raveling, cracking, moisture damages, and oxidation (Brown et al. 2004).

In contrast, the coarse-graded asphalt mixtures behaved differently in a study to identify the percentage of air voids at which the pavement structure becomes excessively permeable. It was found that sometimes the coarse-graded mixes experience high permeability rates even when the air voids are below 8\% (Choubane et al. 1998). Earlier studies concluded that the coarsegraded mixes have higher permeability coefficients than the fine-graded mixes for a particular air void content (Roberts et al. 1996). This is likely the result of the different content of interconnected air voids in both types of mixes where coarse-graded mixes will likely have more interconnected air voids than fine-graded mixes.

In recent years, numerous research works have been performed in a number of states in an attempt to study the permeability characteristic and ultimately recommend a reliable test method or acceptance permeability criteria (Choubane et al. 1998; Maupin 2000; Cooley et al. 2001; Mogawer et al. 2002; Brandon et al. 2004; Owusu-Ababio and Schmitt 2009; Tarefder and Ahmad 2015). Other studies have attempted to propose permeability limits to be added to the current quality assurance (QA) and quality control (QC) (Williams et al. 2009; Williams, 2011; Chen et al. 2013). Despite this growing concern of HMA permeability, little efforts were devoted to understand the interrelationship between permeability, in the field and laboratory, and other important mechanical and physical pavement characteristics. If these relationships are 
investigated and quantified, the possibility of incorporating the permeability within the mix design procedure will not only be highlighted and addressed, but also field permeability prediction based on laboratory procedure can be ultimately achieved.

\section{OBJECTIVES}

The main objective of this paper is to investigate if pavement permeability can be used as a pavement construction quality control/quality (QC/QA) assurance criterion by exploring the relationship between pavement permeability and the pavement's resistance to loading, which is evaluated using the mechanical characteristic indirect tensile strength (IDT), and current pavement construction QC/QA criteria, the most important of which is the physical characteristic relative density (RD). Furthermore, the paper investigates the variability of pavement permeability with the test setting (field and laboratory) and the variability of the mechanical and physical pavement characteristics across the pavement lane width.

\section{DATA COLLECTION AND STUDY SCOPE}

The experimental program in this study consisted of two major phases; the field and laboratory as illustrated in Error! Reference source not found.. The field phase dealt with measuring the field permeability as well as recovering field cores from the exact location where the field permeability test was conducted. In the laboratory phase, several laboratory specimens were prepared using the same mixtures studied in the field. In addition, different laboratory tests including the RD, laboratory permeability, and IDT were carried out on both the laboratoryprepared SGC specimens and field-recovered cores.

The site selection for inspection and sampling included both highway projects and inhouse field trials located in Ontario's Eastern Region. The term "in-house" is used in this paper 
to refer to non-highway field projects performed at controlled locations/sections under the supervision of the construction firm R.W. Tomlinson Limited. In addition, the site selection of this study incorporated both newly constructed asphalt pavement surfaces and other in-service roads. The term "in-service" refers to sites that were compacted and tested in a previous year. These in-service sections were evaluated to quantify the short-term effect of traffic densification on the field permeability of the road surface. In total, 130 field permeability tests were carried out, 88 field cores were recovered, and 33 laboratory samples were prepared. The full study plan implemented in this research is summarized in Table 1. It should be noted that the layer thickness shown in Table 1 was estimated based on the extracted/recovered core thickness. The HMA pavements in this research were all Superpave mixes with a nominal maximum aggregate size (NMAS) of $12.5 \mathrm{~mm}$.

At each test site, a total of five testing locations were selected along the cross-section of a roadway lane to examine the variability in pavement physical and mechanical characteristics with the change of lateral location of the testing location. For each testing location (diameter $=$ $150 \mathrm{~mm}$ ), a pavement core was then recovered and transported to the Civil Engineering Laboratory at Carleton University for further experimental investigations as explained earlier. Error! Reference source not found. illustrates the testing locations incorporated in this research and their corresponding distances from the edge of the paved lane.

\section{EXPERIMENTAL PROGRAM}

\subsection{Field and Laboratory Tests}

As explained in the previous section, the research scope incorporated four different experiments including one field and three laboratory tests which are setup as shown in Error! Reference source not found.. Firstly, the field permeability of the selected HMA pavement 
sites was evaluated using the National Center for Asphalt Technology (NCAT) field permeameter shown in Error! Reference source not found.a. The test instructions outlined in the operating manual of the NCAT permeameter AP-1B were followed (NCAT 2015). Secondly, the bulk specific gravity $\left(G_{\mathrm{mb}}\right)$ or bulk relative density (BRD) of a compacted HMA samples was determined using the saturated surface dry (SSD) method outlined in the ASTM D2726/D2726M-14 (ASTM 2014) as presented in Error! Reference source not found.b. Relative density (RD) was then calculated as the ratio of the BRD to the maximum relative density (MRD). Upon completion of the RD test, the laboratory permeability test was carried out using the Karol-Warner Asphalt permeameter (Error! Reference source not found.c) and according to the Florida Test Method FM 5-565 (Florida DOT 2012). Finally, the IDT test was conducted in accordance with ASTM D6931standard test method for IDT of bituminous mixtures (ASTM 2012) as Error! Reference source not found.d depicts. It is worth noting that the permeability or hydraulic conductivity, an important characteristic of pavement materials, was measured and represented by the permeability coefficient $(k)$ in $\mathrm{mm} / \mathrm{sec}$ in both testing setups; field and lab.

\subsection{The Superpave Gyratory Compactor (SGC)}

The SGC was used to compact loose mixes provided by the MTO at different compaction levels to simulate different densities achieved in the field. Before the compaction stage using the SGC, four parameters were considered and calibrated (according to the SGC user's manual) including the specimen height, consolidation pressure, ram speed, and turntable RPM. During compaction, the consolidation pressure was set at $600 \mathrm{kPa}$, with an angular velocity of 30 gyrations/min, and gyratory angle of $1.25^{\circ}$. Four different loose asphalt mixtures corresponding to the same mixes studied in the field were used to prepare the SGC specimens. It should be 
noted that SGC specimens were prepared using the asphalt mixtures of the four highway projects (Highway 15, 16, 17, and 417) while there was no loose mixture available for any of the in-house sites. The mix designs for each mix are shown in Table 2.

Several trials or iterations were performed in order to quantify the amount of loose mixture required to produce SGC specimens with the targeted compaction levels. After producing a SGC specimen of anticipated compaction level, RD of that specimen was checked. If RD did not fall within the level specification range, a new specimen was prepared. This iterative process was performed until the desirable amount of material to reach each desired compaction level was determined. The four compaction levels, A to D, are described in Table 3.

For the last three compaction levels (B, C, and D), the weight of loose mix as well as the specimen height were entered while not specifying the number of gyrations. This means that the numbers of gyrations for the compaction levels B, C, and D were varied and the SGC selected the appropriate number of gyrations needed for each level. It is important to note that as the compaction effort decreased, the specimen height had to be reduced to avoid having loosely bound specimens with incoherent edges. Therefore, Table 3 shows the specified specimen height decreasing with the decrease in compaction effort and is lowest for level D. This difference in specimen height did not affect the results because the calculations for permeability coefficient and IDT consider the specimen dimensions including height.

On the other hand, for compaction level A, the number of gyrations was set to the maximum number which is 998 gyrations for all mixes rather than the maximum number of gyrations $\left(N_{\max }\right)$ for each mix. Subsequently, the specimen height, which was not defined as an input, was measured after compaction and was found to range from 103 to $110 \mathrm{~mm}$ depending on the mixture type. RD for compaction level A specimens produced in this way ranged from $97 \%$ 
to $99 \%$. It is important to note that due to the limited quantities of loose asphalt mixture of Highways 15, 16 and 17, only seven specimens were produced at different compaction levels while twelve specimens were prepared using Highway 417 mix.

\section{RESULTS AND DISCUSSIONS}

\section{$5.1 \quad$ Field Observations}

During the field testing, an important observation was noted on several test locations where the water penetrated the surface into the body of the asphalt mix and appears to have moved sideways within the layer and returned upward outside the test region (Error! Reference source not found.a and Error! Reference source not found.b). This observation suggests two findings. First, the vast majority of the air voids within the finished paved lane were mostly interconnected forming a channel leading the water back again to the surface. Second, the water underneath the testing location flows in a three-dimensional pattern. These two findings are most likely the main important factors to explain the mechanism behind the development of potholes.

\subsection{RD-IDT Relationship}

The relationship between RD and IDT was explored for the field-recovered cores and SGC specimens. Non-linear regression analysis was carried out using SPSS 20.0 software to develop the RD-IDT relationship. For the SGC specimens, a very strong relationship was observed in each of the four mixes as the coefficient of determination $\left(R^{2}\right)$ varies between 0.96 and 0.99 as shown in Error! Reference source not found.a. In general, the presented relationships suggest that as RD increases, IDT increases and vice versa. A similar trend was observed for the field-recovered cores as shown in Error! Reference source not found.b; however, the relationships resulted in $R^{2}$ coefficients ranging between 0.01 (practically no relationship) and 0.68 indicating a weaker relationship compared to the SGC trend. Thus, it can 
be stated that very good estimates of the pavement's mechanical properties in the lab can be reached using RD. The quality of this estimation deteriorates for the mechanical properties of the actual pavement project in the field, but fair estimates can still be made using RD.

\subsection{RD-Permeability Relationship}

The relationship between $\mathrm{RD}$ and pavement permeability was examined using the three different measurements of the permeability coefficient which are laboratory measurement of SGC specimens, laboratory measurement of field-recovered cores, and field measurements. First, the relationship was explored for each mix separately based on the results of the 33 laboratoryprepared SGC specimens as presented in Error! Reference source not found.a. As can be seen, the plotted trend lines follow a strong exponential trend $\left(0.80<R^{2}<0.97\right)$ for all four mixes in this research. The general trend shows that as the achieved RD level decreases, the permeability coefficient increases. This trend is expected since higher $\mathrm{RD}$ values means lower air void content and thus less chances of having interconnected paths for water to move through. Furthermore, any interconnected air voids at high RD would likely have narrow channels where water cannot flow easily, thereby reducing permeability. However, the trends also show that the permeability coefficient increases at a slow rate with the decrease in RD until a certain transition zone (from $92 \%$ to $90 \%$ ) where the permeability values start to increase rapidly with further decreases in RD. This suggests that below a specific relative density level, the asphalt pavement will likely become excessively permeable. The relationships based on the field-recovered cores in Error! Reference source not found.b had a similar trend, yet with moderate $R^{2}$ values $\left(0.34<R^{2}<0.69\right)$. Finally, the relationships based on field measurements in Error! Reference source not found.c exhibited the weakest relationship between $\mathrm{RD}$ and permeability coefficient as the $R^{2}$ values were between 0.05 and 0.32 . The results indicate that variations in $\mathrm{RD}$ alone cannot explain the 
variability in field permeability or pavement's tensile strength even though the relationships are very strong in the lab test setting.

\subsection{IDT-Permeability Relationship}

The previous relationships between RD and both IDT and permeability varied in their strength depending mainly on the test setting for measuring the permeability coefficient. It was therefore expected to observe the same difference in the IDT-permeability relationship at the three different permeability test settings. Error! Reference source not found.a depicts the relationship between the lab permeability and IDT for the SGC specimens of different asphalt mixes. In all mixes, it is obvious that a strong relationship exists between the permeability coefficient and IDT as $R^{2}$ ranges between 0.77 and 0.93 . This could be attributed to the fact that stronger bonds between the aggregate and asphalt binder (cohesion) as well as stronger bonds within the binder itself (adhesion) exist in any given specimen of high IDT value. In general, higher RD values (or less air voids content) will likely contribute to a stronger internal structure. This reduction in air voids content occurs as the asphalt binder content filling the air void space. These structural changes caused by increasing RD or IDT will likely reduce the possibility of having interconnected paths and increase the isolated voids content. Consequently, lower permeability is expected since it is highly dependent upon the interconnected air voids content. For the second test setting based on the field-recovered cores, fair relationships $\left(0.33<R^{2}<0.78\right)$ were observed between the IDT and the permeability coefficient as presented in Error! Reference source not found.b; however, the relationships were not as strong as the relationships based on the SGC specimens. It can be seen also in both Error! Reference source not found.b and Error! Reference source not found.b that the variability in lab permeability is better explained by the IDT $\left(0.33<R^{2}<0.78\right)$ as opposed to RD $\left(0.34<R^{2}<0.69\right)$. After a closer look at 
the two figures (Error! Reference source not found.b and Error! Reference source not found.b), it can be seen that as the values on the $\mathrm{x}$-axis increase, IDT values exhibit stronger correlations when compared to the RD values. Finally, the permeability test setting based on field measurements exhibited (Error! Reference source not found.c) the lowest $R^{2}$ values, except for only one site, which confirms the previously presented poor relationships in Error!

\section{Reference source not found.c.}

Finally, comparing Error! Reference source not found.a and Error! Reference source not found.b shows that the field-recovered cores and laboratory-prepared SGC specimens of the same mix design have different IDT values. The SGC specimens have almost twice the strength of the field-recovered cores. It should be noted that the SGC was developed to better simulate pavement compaction in the field, by utilizing a combination of pressure and kneading actions compared to the hammering action in Marshall compactor. Therefore, the difference in compaction mechanism between the lab and field is likely the source of this considerable difference in IDT. The difference cannot be explained by air voids or relative density. The constructed pavement in the field has a reduced resistance to loading compared to laboratoryprepared samples with the same air voids. This difference can be explained by the presence of construction-induced cracks which are observed in the field but not in the SGC specimens produced in the lab (Abd El Halim and Mostafa 2006; Abd El Halim et al. 2009; Abd El Halim et al. 2013).

\subsection{Field-Lab Permeability Relationship}

The previous analysis suggested that although field and lab measurements of the permeability coefficient follow similar trends, their level of association to other mix properties (such as RD and IDT) can vary considerably. It is therefore important to understand the 
relationship between the field and lab permeability coefficients. First, a $t$-test at $5 \%$ level of significance was carried out to examine if there is a significant difference between the permeability coefficient as determined in the two test settings: field measurement and laboratory measurement of field-recovered cores. For each site, the null $\left(H_{0}\right)$ and alternative $\left(H_{1}\right)$ hypotheses were as follows:

$$
\begin{aligned}
& H_{0}=\mu_{\text {field permability }}=\mu_{\text {lab permeability }} \\
& H_{1}=\mu_{\text {field permability }} \neq \mu_{\text {lab permeability }}
\end{aligned}
$$

The $p$-value for three different sites where the field and lab measurements of the fieldrecovered cores were available (Highway 16, 17 and 417) were 0.012,<0.001, and 0.046, respectively. These $p$-values indicate that there is a statistically significant difference between the field and lab measurements at 5\% level of significance.

The relationship between field permeability measurements and laboratory permeability of field-recovered cores was subsequently examined using results obtained from the three projects with common measurements. In total, 45 points were plotted in a scatter diagram, and a linear relationship was developed. According to Error! Reference source not found., a moderate linear relationship $\left(R^{2}=0.40\right)$ exists between the field and laboratory measurements. In addition, the vast majority of field permeability measurements were below the 1:1 line which indicates that the field permeability was higher than the laboratory permeability nearly all the time.

The significant difference between the field and lab permeability could be attributed to several reasons. First, each device has its own measurement mechanism to estimate the permeability coefficient despite the fact that both of them are based on the falling head principle. More specifically, in the NCAT permeameter the water has the flexibility to diffuse in vertical 
and lateral directions within the pavement structure. However, the permeability calculation using the NCAT device assumes that the water will flow in one dimension (vertically down) through the $150 \mathrm{~mm}$ diameter test area which is not an accurate assumption. In other words, the measured permeability is likely a combination of two directional permeability; the vertical and horizontal. On the other hand, the measurement mechanism of the Karol-Warner Asphalt permeameter forces the water to move only through the pavement thickness by applying a confining pressure of $68.9 \pm 3.4 \mathrm{kPa}$ to the attached rubber membrane. This setup is more consistent with the theoretical basis for calculating the permeability coefficient according to Darcy's law. In particular, the steady state flow condition as well as the saturation can be easily met. In fact, one can control the specimen saturation condition in the laboratory to reach a specific level in order not to violate Darcy's law; this is not possible during the field permeability test. In reality, however, the accumulated water on HMA surfaces caused by rainfalls will fall on the whole pavement surface, and for it to penetrate the surface and then move into the pavement structure, it will most likely flow in one direction downward. Thereby, the HMA permeability based on laboratory measurements will likely reflect and simulate the actual field condition.

Several prediction models relating the field permeability to the laboratory permeability of field-recovered cores have been developed in the literature. Table 4 summarizes the developed model by each study, the associated coefficient of determination $\left(R^{2}\right)$, and the regression model type. The existing models were compared to the developed linear model in this study and the actual field-laboratory data as shown in Error! Reference source not found.. The plotted data suggests that for a specific range of field permeability coefficient $(20 \mathrm{~mm} / \mathrm{sec}$ to $100 \mathrm{~mm} / \mathrm{sec})$, Prowell and Dudley's model is the closest model to the data and developed model in this study followed by William's model and Kantipong Model's. All four models were below the 1:1 line 
indicating that all models predict field permeability to be greater than the laboratory permeability for the same reasons previously discussed in the preceding subsection. Although the four models successfully explained almost half of the actual field data, some of the actual field data points tend to be slightly higher than the four models. In other words, the four models fall closer to the 1:1 line as opposed to some of the actual field data points.

\subsection{Effect of Testing Location, Project Level, and Short-Term Compaction due to Traffic}

The impact of two different independent factors, termed as the testing location and project level, on each pavement characteristic (response variable) was examined using a two-way analysis of variance (ANOVA) test at 5\% level of significance. The term project level refers to the different pavement projects or highways investigated in this study. Before conducting any of the statistical tests, the Levene's test of homogeneity of variances was performed to check whether the examined datasets have equal variance or not. In case of not meeting the homogeneity of variances assumption, the results assuming unequal variances were considered. Summary of the two-way ANOVA results is shown in Table 5. As shown in the table, the project level has a significant effect for the four pavement characteristics as all $p$-values were less than $5 \%$. For the testing location factor, all pavement characteristics had insignificant effect, except for the laboratory permeability of field-recovered cores. This indicates that the Karol-Warner Asphalt permeameter showed a difference in permeability coefficient for the various testing locations. Also, the laboratory permeability was the only pavement characteristic that had a significant two-way interaction effect. This implies that the effect of the project level on the lab permeability depends significantly on the testing location and vice versa.

The short-term effect of age and traffic on field permeability was also studied separately in this research. The field permeability measurements were available for two consecutive years 
(the as-built and one year later) for three sites. A $t$-test at $5 \%$ level of significance was used to examine the difference between the measurements of the two years. The $t$-test results summarized in Table 6 indicate that in two out of three sites, statistically insignificant difference was noticed at $5 \%$ level of significance.

\section{CONCLUSIONS}

The main objective of the paper was to explore the relationship between important pavement characteristics, which are RD, IDT, and permeability in both lab and field test settings. First, RD was related to the permeability to examine the strength of both the RD-field permeability and RD-lab permeability relationships. It was found that $\mathrm{RD}$ has a strong relationship to lab permeability of SGC specimens but the strength of this relationship decreases when lab permeability is measured for field-recovered cores and is very weak when the permeability is measured in the field. The same trend was found for the relationship between IDT and permeability. The agreement of the trends of relationship between permeability and both RD (a good indicator of the physical characteristics) and IDT (a good indicator of the mechanical characteristics) affirms the difference between field and lab permeability. This difference, which can explain why some pavements fail prematurely even though they perform well in the lab, was tested statistically and was found to be significant at $5 \%$ level of significance. Finally, it was observed that a moderate relationship existed between RD and IDT of field-recovered cores which suggests that RD can be a reasonable predictor of IDT (and thus short-term pavement performance). On the other hand, both RD and IDT had weak relationships with field permeability, which indicates that neither characteristic can be a good predictor of field permeability (and thus long-term pavement performance). Therefore, measuring the pavement permeability in the field can help in evaluating the expected long-term performance of 
a pavement project. Given that field permeability is measured using a fairly easy, nondestructive test, it can be valuable tool in QC/QA of hot-mix asphalt pavement projects.

\section{ACKNOWLEDGEMENT}

The financial and technical support for this research-project by the Ministry of Transportation of Ontario (MTO), R.W. Tomlinson Limited, and Natural Sciences and Engineering Research Council (NSERC) is gratefully acknowledged. The valuable assistance of Anandkumar Chelliah is highly appreciated.

\section{REFERENCES}

Abd El Halim A. O., and Mostafa A. 2006. Asphalt Multi-Integrated Rollers and Steel Drum Compactors: Evaluating Effect of Compaction on Permeability of Asphalt Pavements. Transportation Research Record: Journal of the Transportation Research Board. Transportation Research Board of the National Academies, Washington, D.C, 1967: 173-180. doi: http://dx.doi.org/10.3141/1967-17.

Abd El Halim A. O., Said D., and Mostafa A. 2009. A Protection of the Environment Through the Prevention of Surface Cracking. The Open Civil Engineering Journal, 3: 7-15. doi: $10.2174 / 1874149500903010007$.

Abd El Halim A. O., Pinder F., Chelliah A., Abdelalim O. 2013. Reducing Maintenance and Rehabilitation Costs through the Use of AMIR Compaction. Horizon Research, 1(3), 51-60. doi: 10.13189/cea.2013.010301.

ASTM. 2012. Standard Test Method for Indirect Tensile (IDT) Strength of Bituminous Mixtures (D6931-12), West Conshohocken, PA. doi: 10.1520/D6931-12. 
ASTM. 2014. Standard Test Method for Bulk Specific Gravity and Density of Non-Absorptive Compacted Bituminous Mixtures (D2726 / D2726M-14), West Conshohocken, PA. doi: 10.1520/D2726_D2726M-14.

Brandon, J. M., Jared D. M., Wu P. Y., and Geary G. M. 2004. Field and Laboratory Investigation of Permeable Asphalt Mixes on Georgia Highways. Transportation Research Record: Journal of the Transportation Research Board. Transportation Research Board of the National Academies, Washington, D.C, 1891: 32-39. doi: http://dx.doi.org/10.3141/1891-05.

Brown, E. R., Hainin M. R., Cooley L. A., and Hurley G. 2004. Relationship of Air Voids, Lift Thickness, and Permeability in Hot Mix Asphalt Pavements. NCHRP Report 531, Transportation Research Board of the National Academies, Washington, D.C.

Caro, S., Masad E., Bhasin A., and Little D. 2010. Coupled Micromechanical Model of Moisture-Induced Damage in Asphalt Mixtures. Journal of Materials in Civil Engineering, 22(4): 380-388. doi: 10.1061/(ASCE)MT.1943-5533.0000031.

Chen, C., Williams R. C., EI.T. A., Lee H., and Schram S. 2013. Quality control/quality assurance testing for longitudinal joint density and segregation of asphalt mixtures. Construction and Building Materials, 47: 80-85. doi: 10.1016/j.conbuildmat.2013.05.007.

Chen, J. S., Lin K. Y., and Young S. Y. 2004. Effects of Crack Width and Permeability on Moisture-Induced Damage of Pavements. Journal of Materials in Civil Engineering, 16(3): 276282. doi: 10.1061/(ASCE)0899-1561(2004)16:3(276).

Choubane, B., Page G., and Musselman J. 1998. Investigation of Water permeability of Coarse Graded Superpave Pavements. Journal of the Association of Asphalt Paving Technologists, 67: 254-276. 
Cooley, L. A., Jr., Brown E. R., and Maghsoodloo S. 2001. Developing Critical Field Permeability and Pavement Density Values for Coarse-Graded Superpave Pavements. Transportation Research Record: Journal of the Transportation Research Board. Transportation Research Board of the National Academies, Washington, D.C., 1761: 41-49. doi: http://dx.doi.org/10.3141/1761-06.

Florida DOT. 2012. Florida Test Method for Measurement of Water Permeability of Compacted Asphalt Paving Mixtures (FM 5-565). Florida: Department of Transportation.

Howson, J., Bhasin A., Masad E., and Lytton R. 2009. Development of a Database for Surface Energy of Aggregates and Asphalt Binders. Report 5-4524-01-1, Texas Transportation Institute, Austin, Texas.

Kanitpong, K., Bahia, H., Russell, J., and Schmitt, R. 2002. Predicting Field Permeability from Testing Hot-Mix Asphalt Specimens Produced by Superpave Gyratory Compactor. Transportation Research Record: Journal of the Transportation Research Board. Transportation Research Board of the National Academies, Washington, D.C., 1929: 52-58. doi: 10.3141/192907.

Kennedy, T. W., Huber G. A., Harrigan E. T., Cominsky R. J., Hughes C. S., Quintus H. V., and Moulthrop J. S. 1994. Superior performing asphalt pavements (Superpave): The product of the SHRP asphalt research program. Report SHRP-A-410, Strategic Highway Research Program, National Research Council, Washington, D.C.

Kim, Y. R., Little D. N., and Lytton R. L. 2004. Effect of Moisture Damage on Material Properties and Fatigue Resistance of Asphalt Mixtures. Transportation Research Record: Journal 
of the Transportation Research Board. Transportation Research Board of the National Academies, Washington, D.C., 1891: 48-54. doi: 10.3141/1891-07.

Mallick, R. B., Cooley L. A., Teto M. R., Bradbury R. L., and Peabody D. 2003. An Evaluation of Factors Affecting Permeability of Superpave Designed Pavements. Report 03-02, National Center for Asphalt Technology (NCAT), Auburn.

Maupin, G. W. Jr. 2000. Asphalt Permeability Testing in Virginia. Transportation Research Record: Journal of the Transportation Research Board. Transportation Research Board of the National Academies, Washington, D.C, 1723: 83-91. doi: 10.3141/1723-11.

McLaughlin, J. F., and Goetz H. W. 1955. Permeability, Void Content, and Durability of Bituminous Concrete. In Proceedings of the Thirty-Fourth Annual Meeting of the Highway Research Board, Washington, D.C. 11-14 January 1955. TRB, pp. 274-286.

Mogawer, W. S., Mallick R. B., Teto M. R., and Crockford W. C. 2002. Evaluation of Permeability of Superpave Mixes. NETCR Report 34. The New England Transportation Consortium, Storrs, CT.

NCAT. 2015. Operating Manual NCAT Asphalt Field Permeameter Kit AP-1B. GlobalGilson, Lewis Center, Ohio. Available from https://www.globalgilson.com/docs/productmanuals/Manual_AP-1B.pdf [cited 12 December 2015].

Owusu-Ababio, S., and Schmitt R. L. 2009. A Framework for Performance-Based Permeability and Density Acceptance Criteria for HMA Pavements in Wisconsin. In Proceedings of the 2009 Mid-Continent Transportation Research Symposium, Ames Iowa, United States, 20-21 August 2009. 
Pang, C. Q. 2012. Research on the Moisture Damage Occurred on the Asphalt Pavement. Applied Mechanics and Materials, 178: 1117-112. doi: 10.4028/www.scientific.net/AMM.178181.1117.

Prowell, D. B., and Dudley, C. M. 2002. Evaluation of Measurement Techniques for Asphalt Pavement Density and Permeability. Transportation Research Record: Journal of the Transportation Research Board. Transportation Research Board of the National Academies, Washington, D.C., 1789: 36-45. doi: 10.3141/1789-04.

Roberts, F. L., Kandhal P. S., Brown E. R., Lee D. Y., and Kennedy T. W. 1996. Hot Mix Asphalt Materials, Mixture Design, and Construction, 2nd ed. NAPA Educational Foundation, Lanham, Maryland.

Tarefder, R. A., and Ahmad M. 2015. Evaluating the Relationship between Permeability and Moisture Damage of Asphalt Concrete Pavements. Journal of Materials in Civil Engineering, 27(5): 04014172. doi: 10.1061/(ASCE)MT.1943-5533.0001129.

Umiliaco, A., and Benedetto A. Aggregate Size Distribution and Hydraulic Permeability of HMA: A Full Simulation Study. 2013. In Proceedings of the Airfield and Highway Pavement Conference, Los Angeles, California, United States, 9-12 June 2013. ASCE pp. 1134-1144. doi: $10.1061 / 9780784413005.095$.

Williams, R. C. 2009. Early Permeability Test for Asphalt Acceptance. Final Report No. OR09017, Missouri Department of Transportation, Jefferson City.

Williams, S. G. 2011. Density, Permeability, Infiltration, and Absorption Used to Assess Quality of Hot-Mix Asphalt Longitudinal Joints. Transportation Research Record: Journal of the 
Transportation Research Board. Transportation Research Board of the National Academies, Washington, D.C., 2228: 120-127. doi: http://dx.doi.org/10.3141/2228-14.

Williams, S. G., Pervis A., Bhupathiraju L. S., and Proter A. 2009. Methods for Evaluating Longitudinal Joint Quality in Asphalt Pavements. Transportation Research Record: Journal of the Transportation Research Board. Transportation Research Board of the National Academies, Washington, D.C., 2098: 113-123. doi: http://dx.doi.org/10.3141/2098-12.

Zube, E. 1962. Compaction Studies of Asphalt Concrete Pavement as Related to the Water Permeability Test. In Proceedings of the 41st Annual Meeting of the Highway Research Board, Washington DC, United States, 8-12 January 1962. TRB, pp. 12-31. 


\section{TABLES}

Table 1: The Research Experimental Plan

\begin{tabular}{|c|c|c|c|c|c|c|c|c|c|c|}
\hline \multicolumn{5}{|c|}{ Site Specifications } & \multicolumn{2}{|c|}{ Field Investigations } & \multicolumn{4}{|c|}{ Laboratory Investigations } \\
\hline Name & Testing Date & $\begin{array}{l}\text { Mix } \\
\text { Type }\end{array}$ & $\begin{array}{c}\text { Layer } \\
\text { Thickness } \\
(\mathrm{mm})\end{array}$ & $\begin{array}{l}\text { Design } \\
\mathrm{AC}(\%)\end{array}$ & $\begin{array}{c}\text { Field } \\
\text { Permeability } \\
(n)\end{array}$ & $\begin{array}{c}\text { FR } \\
\text { Cores } \\
(n)\end{array}$ & $\begin{array}{c}\text { SGC } \\
\text { Samples } \\
(n)\end{array}$ & $\mathrm{RD}$ & $\begin{array}{c}\text { Lab } \\
\text { Permeability }\end{array}$ & IDT \\
\hline Tomlinson In-house & Nov 10, 2012 & SP12.5 RAP & 55 & 5.00 & 7 & 10 & - & FR & $x$ & FR \\
\hline Thousand Islands Parkway & Oct 26, 2012 & SP 12.5 & 45 & 5.10 & 7 & 5 & - & FR & $x$ & FR \\
\hline Highway 28 & Sep 21, 2012 & SP 12.5 & 40 & 4.70 & 10 & 10 & - & FR & $x$ & FR \\
\hline Tomlinson In-house & Nov 21, 2013 & SP12.5 RAP & 55 & 5.00 & 8 & 0 & - & $x$ & $x$ & $x$ \\
\hline Thousand Islands Parkway & Sep 19, 2013 & SP 12.5 & 45 & 5.10 & 9 & 0 & - & $x$ & $x$ & $x$ \\
\hline Highway 28 & May 30, 2013 & SP 12.5 & 40 & 4.70 & 14 & 0 & - & $x$ & $x$ & $x$ \\
\hline Highway 16 & Sep 27, 2013 & 12.5 FC2 RAP & 50 & 4.80 & 15 & 15 & 7 & FR \& SGC & FR \& SGC & FR \& SGC \\
\hline Highway 17 & Sep 25, 2013 & SP 12.5 & 50 & 4.48 & 15 & 15 & 7 & FR \& SGC & FR \& SGC & FR \& SGC \\
\hline Highway 417 & Sep 29, 2013 & $12.5 \mathrm{FC} 2$ & 45 & 4.80 & 15 & 15 & 12 & FR \& SGC & FR \& SGC & FR \& SGC \\
\hline Highway 15 (i) & Oct 2,2013 & $12.5 \mathrm{FCl}$ & 90 & 5.00 & 10 & 10 & 7 & SGC & SGC & SGC \\
\hline Highway 15 (ii) & Oct 29, 2013 & $12.5 \mathrm{FC} 1$ & 90 & 5.00 & 10 & 0 & - & $x$ & $x$ & $x$ \\
\hline Greenbelt Yard & Oct 15, 2014 & $12.5 \mathrm{FC} 2$ & 50 & 5.00 & 3 & 8 & - & FR & FR & FR \\
\hline Total & - & - & & - & 130 & 88 & 33 & $\begin{array}{c}78 \text { FR } \\
33 \text { SGC }\end{array}$ & $\begin{array}{c}53 \text { FR } \\
33 \text { SGC }\end{array}$ & $\begin{array}{c}78 \text { FR } \\
33 \text { SGC }\end{array}$ \\
\hline
\end{tabular}


Table 2: Superpave Mix Designs for the Four Considered Mixes

\begin{tabular}{ccccc}
\hline Site Name & Highway 15 & Highway 16 & Highway 17 & Highway 417 \\
\hline Number of Prepared Specimens & 7 & 7 & 7 & 12 \\
NMAS (mm) & 12.5 & 12.5 & 12.5 & 12.5 \\
Asphalt Binder Content (\%) & 5 & 4.8 & 5 & 4.8 \\
VMA (\%) & 14.6 & 14.6 & 14.4 & 14.2 \\
VFA (\%) & 72.6 & 72.6 & 72.2 & 71.8 \\
Air Void @ N design $(\%)$ & 4 & 4 & 4 & 4 \\
A/C Type & $58-34$ & $64-34 \mathrm{P}$ & $58-34 \mathrm{P}$ & $64-34$ \\
Hot Mix Type & $12.5 \mathrm{FC} 1$ & $12.5 \mathrm{FC} 2$ & SP 12.5 & $12.5 \mathrm{FC} 2$ \\
Maximum Relative Density & RAP & RAP & & \\
$\left(G_{\mathrm{mm}}\right)$ & 2.521 & 2.497 & 2.477 & 2.500 \\
Traffic Category & $\mathrm{D}$ & $\mathrm{E}$ & $\mathrm{C}$ & $\mathrm{E}$ \\
\hline Sieve Size (mm) & Job Mix Formula (JMF) - Gradation Percentage Passing (\%) \\
\hline 25 & 100 & 100 & 100 & 100 \\
19 & 100 & 100 & 100 & 100 \\
12.5 & 96.0 & 98 & 97.9 & 97.4 \\
9.5 & 83.8 & 89.8 & 84.5 & 87.4 \\
4.75 & 57.1 & 61.9 & 53.4 & 63.5 \\
2.36 & 42.1 & 47.1 & 39.5 & 46.3 \\
1.18 & 30.2 & 36.8 & 28.7 & 36.3 \\
0.6 & 22.0 & 28.6 & 21.1 & 28.0 \\
0.3 & 11.9 & 15.3 & 13.9 & 14.1 \\
0.15 & 6.1 & 7.9 & 7.6 & 6.6 \\
0.075 & 3.3 & 4.1 & 4.3 & 3.3 \\
\hline
\end{tabular}

Table 3: Compaction Levels of SGC Specimens

\begin{tabular}{cccccccc}
\hline \multirow{2}{*}{$\begin{array}{c}\text { Compaction } \\
\text { Level }\end{array}$} & $\begin{array}{c}\text { RD } \\
\text { Ranges }\end{array}$ & $\begin{array}{c}\text { Total No. } \\
\text { of } \\
\text { Specimens }\end{array}$ & $\begin{array}{c}\text { Height } \\
(\mathrm{mm})\end{array}$ & $\begin{array}{c}\text { No. of } \\
\text { Gyrations }\end{array}$ & $\begin{array}{c}\text { Input Variables } \\
\text { Weight } \\
(\mathrm{g})\end{array}$ & $\begin{array}{c}\text { Compaction } \\
\text { Temperature } \\
\left({ }^{\circ} \mathrm{C}\right)\end{array}$ & $\begin{array}{c}\text { Final } \\
\text { Height } \\
(\mathrm{mm})\end{array}$ \\
\hline $\mathbf{A}$ & $94<\mathrm{RD}$ & 6 & - & 998 & 4602 & 145 & $103-110$ \\
B & $92<\mathrm{RD}<94$ & 9 & 90 & - & 3260 & 145 & 78 \\
$\mathbf{C}$ & $89<\mathrm{RD}<92$ & 9 & 90 & - & 3081 & 145 & 78 \\
D & $\mathrm{RD}<89$ & 9 & 80 & - & 2320 & 145 & 63 \\
\hline
\end{tabular}


Table 4: Summary of the Existing Field-Lab Permeability Models

\begin{tabular}{cccc}
\hline Study & Model & $\boldsymbol{R}^{2}$ & Type \\
\hline Prowell and Dudley 2002 & $F=7.2178 L^{0.6851}$ & 0.68 & Power \\
Kanitpong et al. 2005 & $F=8.34 e^{0.055 L}$ & 0.80 & Exponential \\
Williams 2009 & $F=\left(\frac{L}{0.4549}\right)$ & 0.91 & Linear \\
Current Study & $F=\left(\frac{L+4.829}{0.4183}\right)$ & 0.40 & Linear \\
\hline where: (F) Field Permeability Coefficient; (L) Laboratory Permeability Coefficient & \\
\hline
\end{tabular}

Table 5: Summary of the Two-Way ANOVA Results

\begin{tabular}{ccccc}
\hline \multirow{2}{*}{ Factor } & \multicolumn{4}{c}{ Response Variables } \\
\cline { 2 - 5 } & Field Permeability & Lab Permeability & RD & IDT \\
\hline Project Level & $<0.001$ & $<0.001$ & $<0.001$ & $<0.001$ \\
Testing Location & 0.529 & 0.001 & 0.466 & 0.128 \\
Testing Location * Project Level & 0.563 & 0.004 & 0.218 & 0.248 \\
\hline
\end{tabular}

Table 6: Summary of the $t$-test Results for Effect of Age and Traffic on Field Permeability

\begin{tabular}{ccc}
\hline Site Name & $\boldsymbol{F}$ & $\boldsymbol{p}$-value \\
\hline Highway 28 & 8.838 & 0.007 \\
Thousand Islands Parkway & 2.988 & 0.106 \\
Tomlinson & 0.667 & 0.429 \\
\hline
\end{tabular}




\section{FIGURE CAPTIONS}

Figure 1: Effect of Interconnected Air Voids and Surface Cracks on Permeability (Not to Scale)

Figure 1(a) : Isolated Air Voids

Figure 1(b) : Interconnected Air Voids

Figure 1(c) : No Surface Cracks

Figure 1(d) : With Surface Cracks

Figure 2: Experimental Program Plan

Figure 3: Field Permeability Testing Layout

Figure 4: Setup Configuration of Field and Laboratory Tests

Figure 4(a) : NCAT Field Permeameter

Figure 4(b) : Bulk Specific Gravity

Figure 4(c) : Karol-Warner Asphalt Permeameter

Figure 4(d) : IDT

Figure 5: The Water Penetrated the Asphalt Surface under the Permeameter and Returned Back to the Surface Outside the Test Location

Figure 5(a) : Highway 17 Site (Top View)

Figure 5(a) : Thousand Islands Parkway Site (Side View)

Figure 6: RD-IDT Relationship

Figure 6(a) : SGC Specimens

Figure 6(b) : Field-Recovered Cores

Figure 7: RD-Permeability Coefficient Relationship.

Figure 7(a): SGC Specimens

Figure 7(b): Field-Recovered Cores

Figure 7(c): Field Measurements

Figure 8: IDT-Permeability Coefficient Relationship.

Figure 8(a): SGC Specimens

Figure 8(b): Field-Recovered Cores

Figure 8(c): Field Measurements

Figure 9: Relationship between Field and Laboratory Permeability Coefficients of Field-Recovered Cores.

Figure 10: The Examined Existing Models against the Developed Model/Actual Data. 
(a)

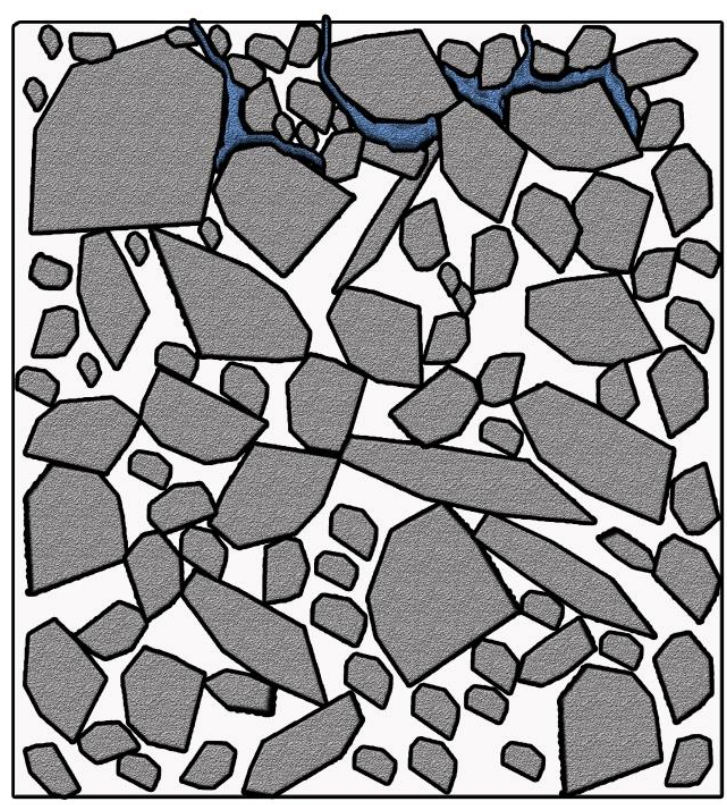

(c)

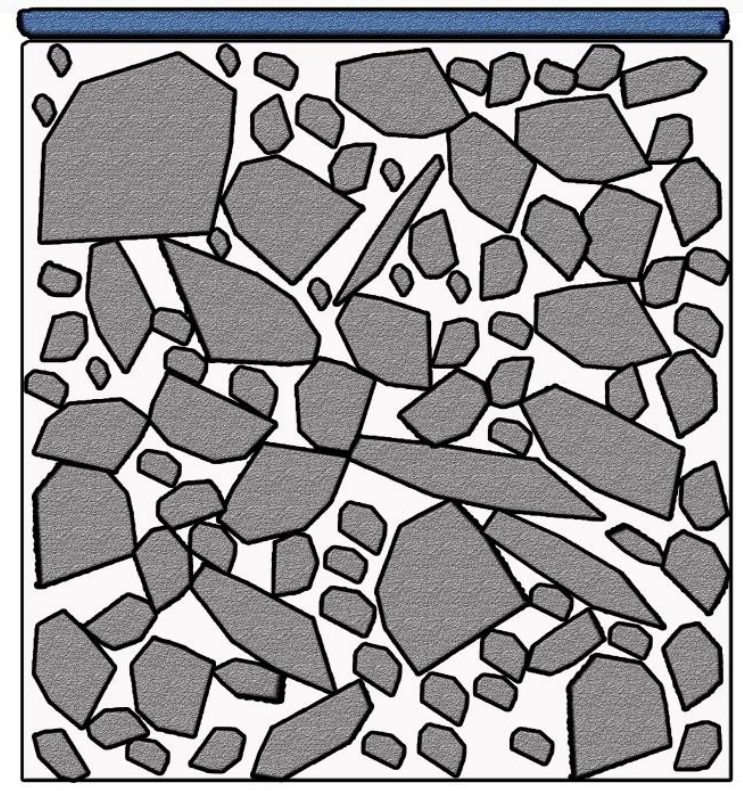

(b)

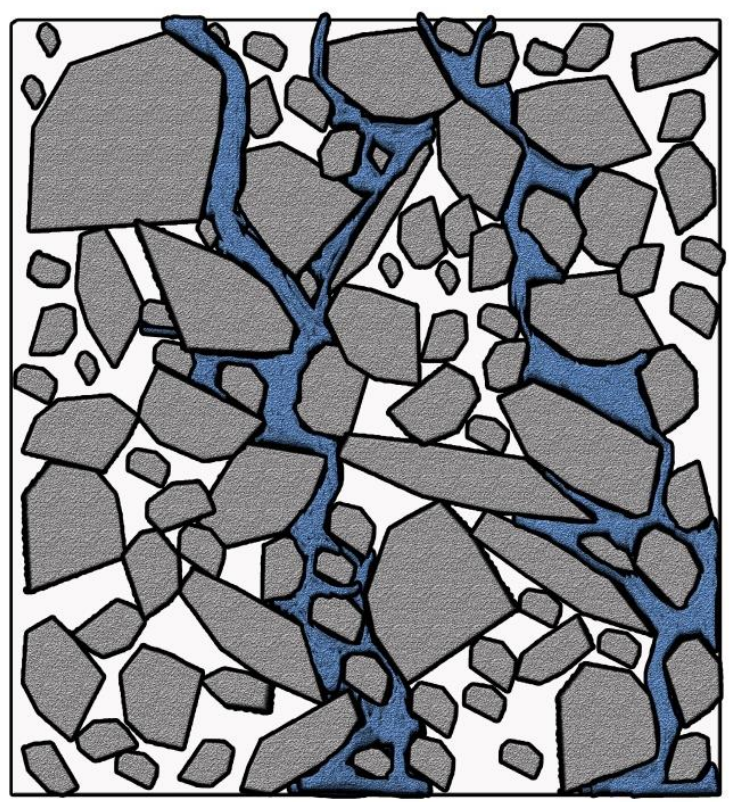

(d)

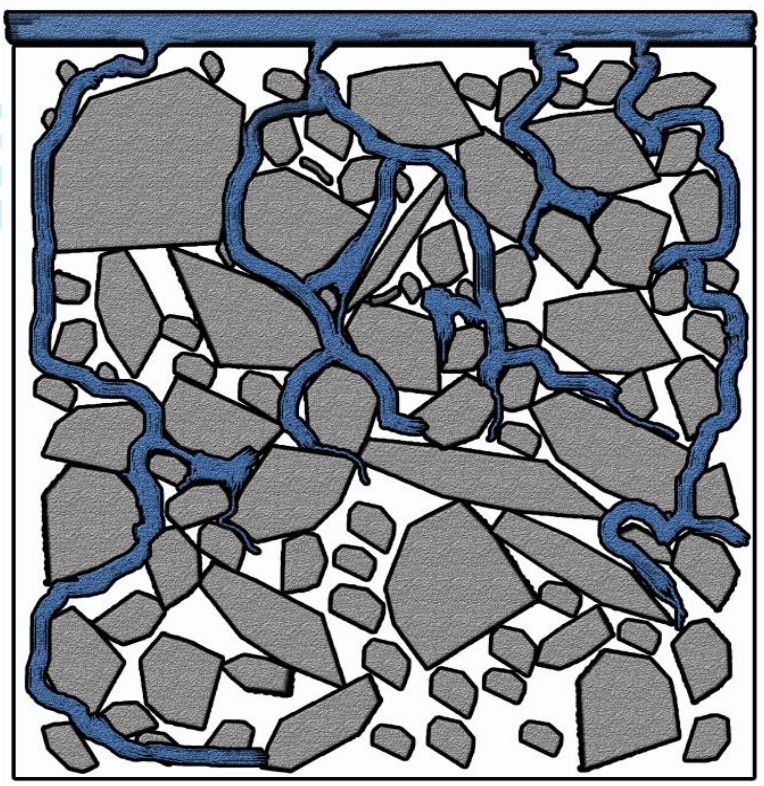




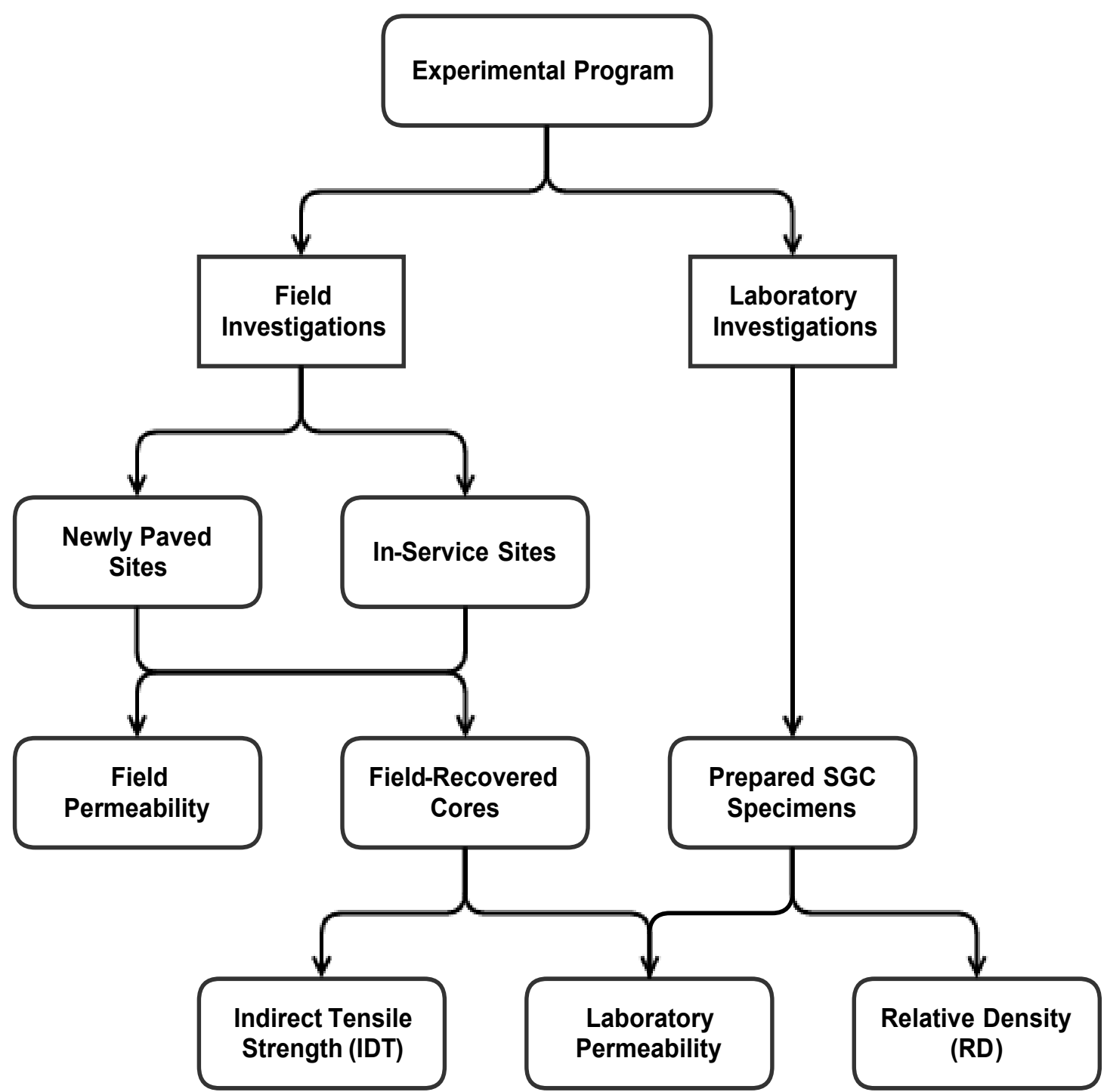




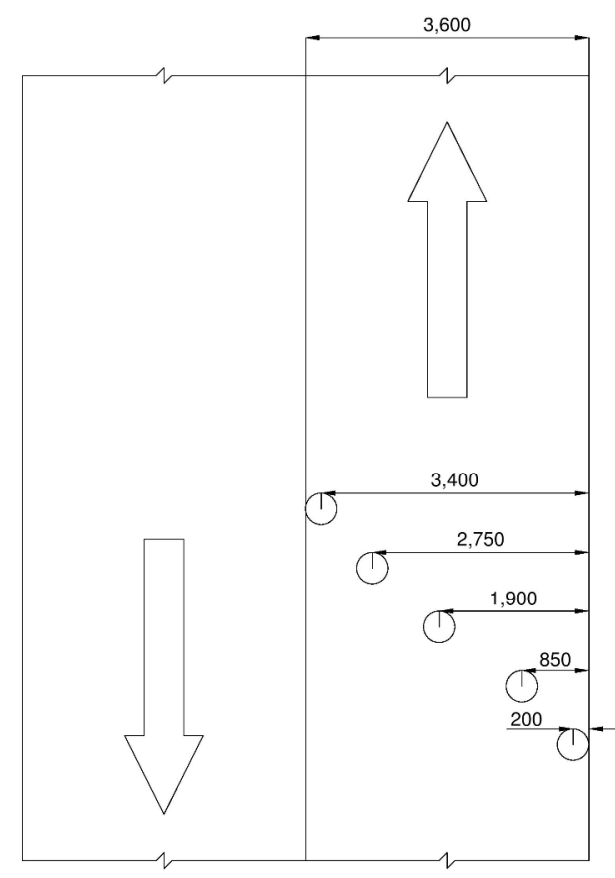

ALL DIMENSIONS ARE IN MILLIMETER

Field Permeability Testing Layout $279 \times 215 \mathrm{~mm}(300 \times 300 \mathrm{DPI})$ 
(a)

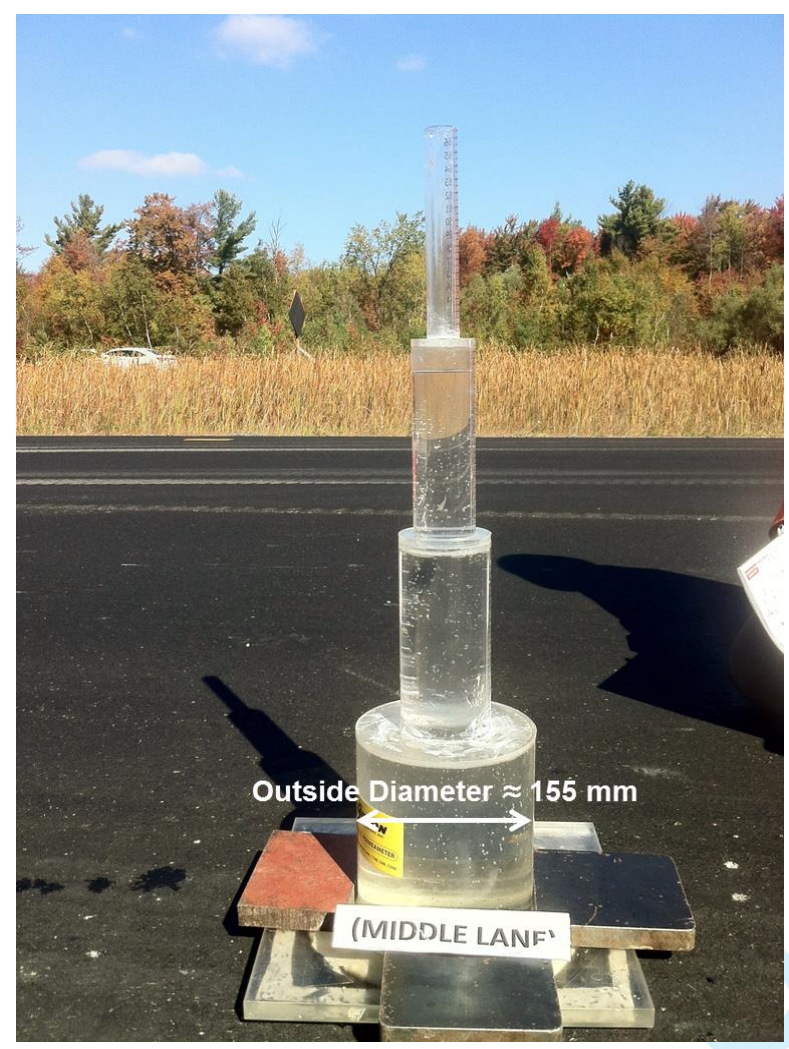

(c)

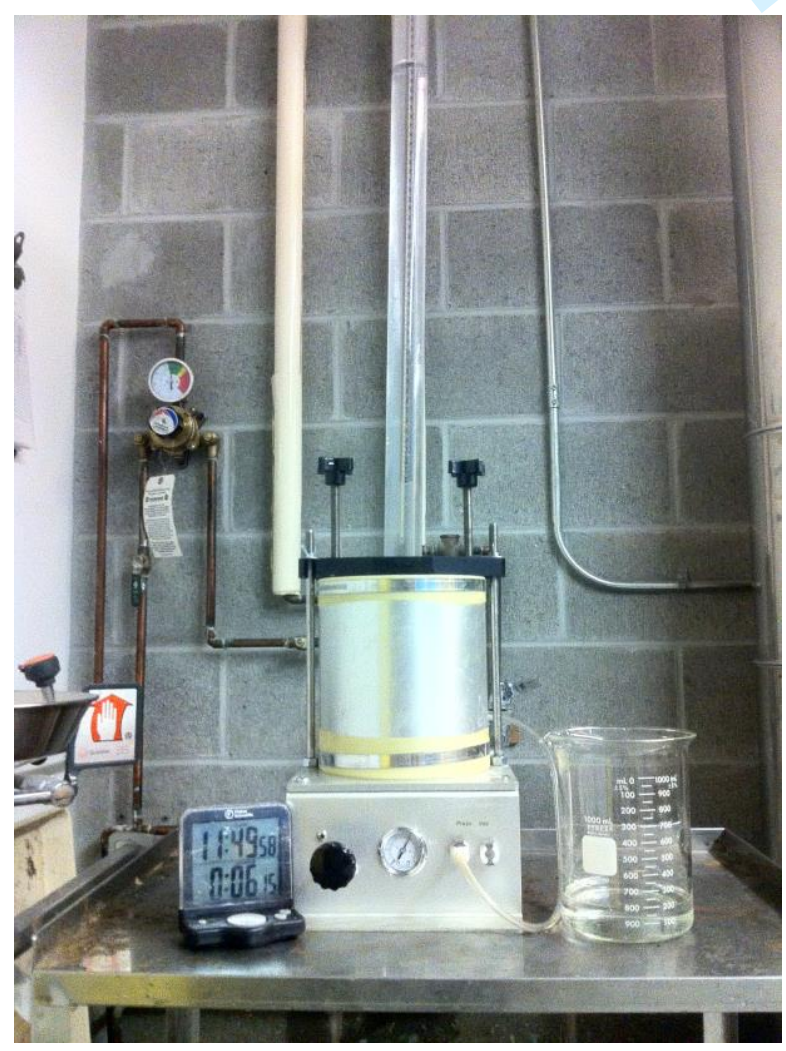

(b)

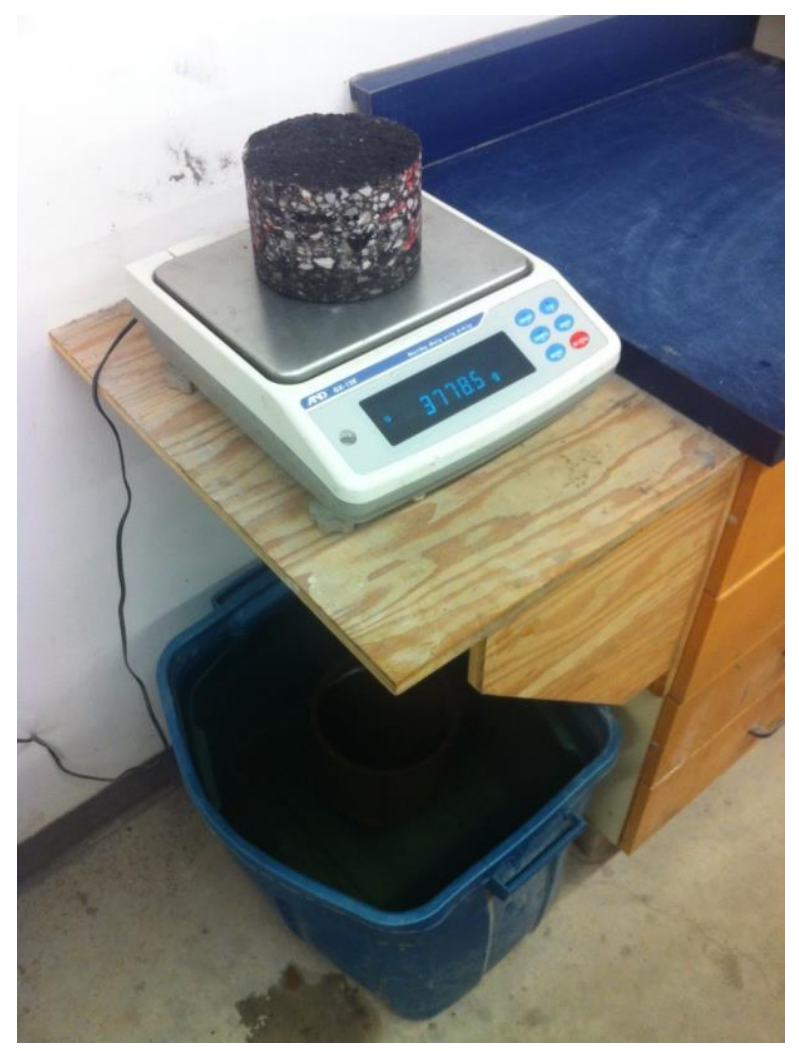

(d)

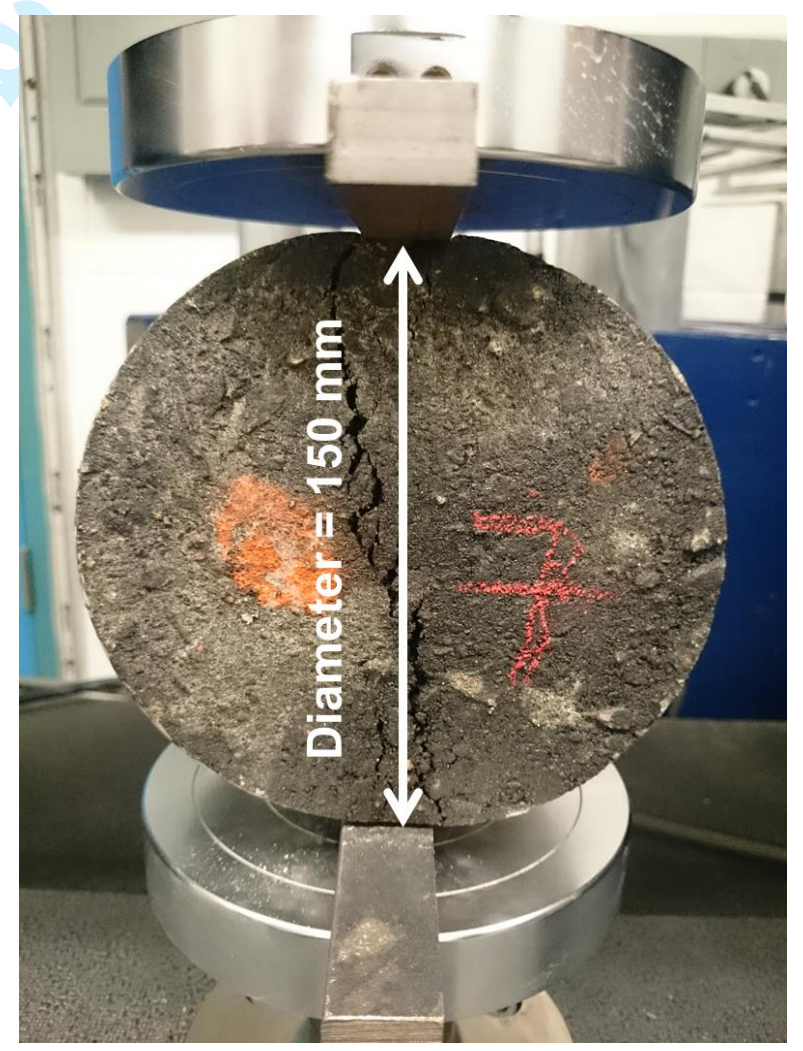


(a)

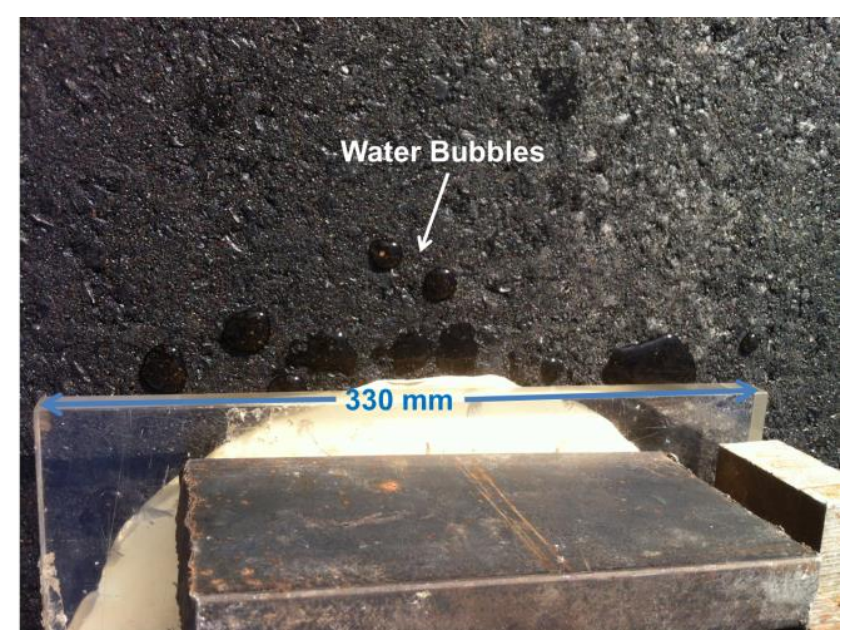

(b)

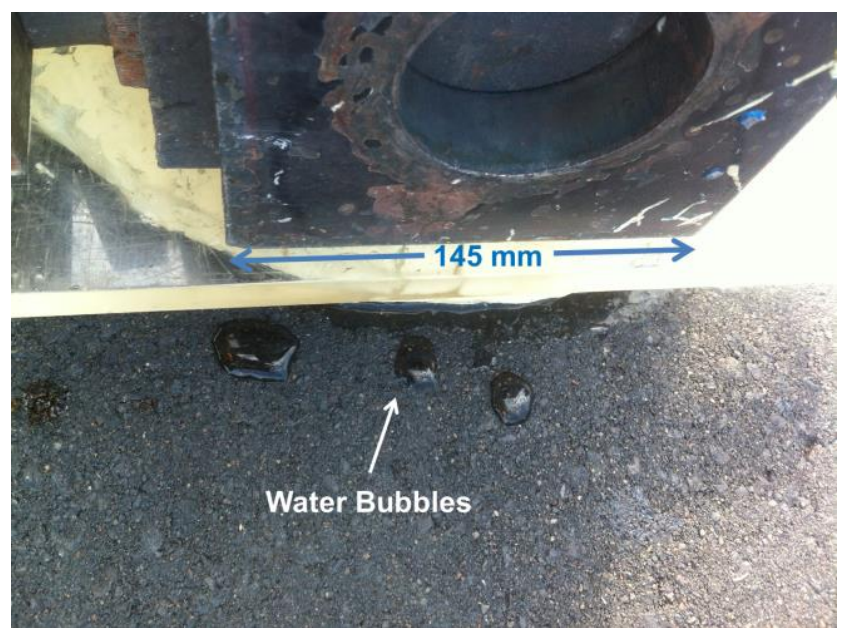


(a)

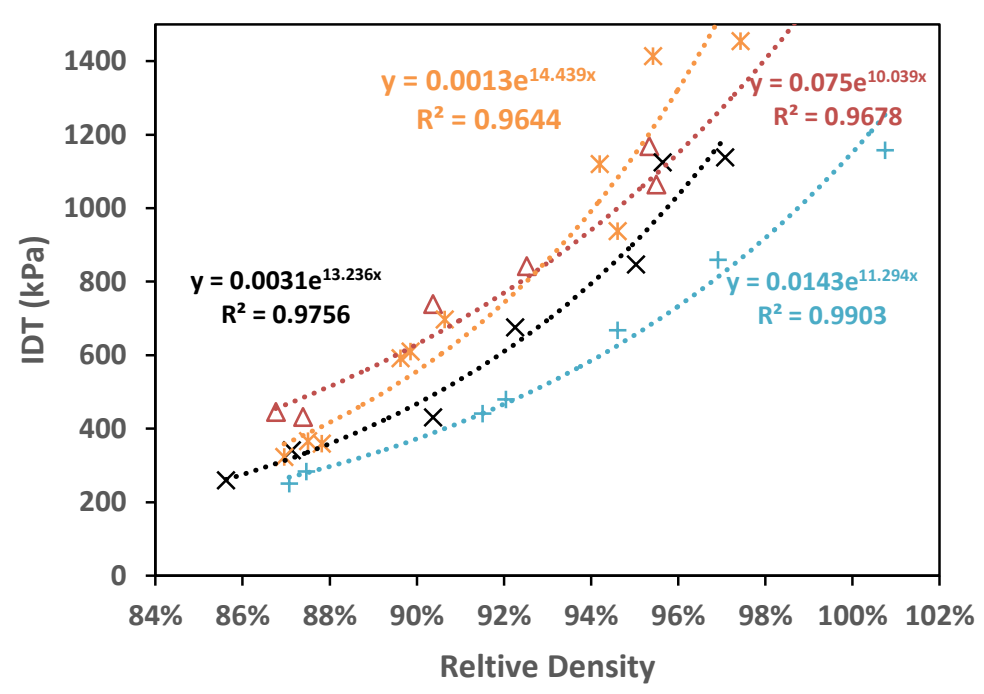

$\triangle$ Highway $15 \quad \times$ Highway $16 \quad+$ Highway $17 \quad *$ Highway 417 (b)

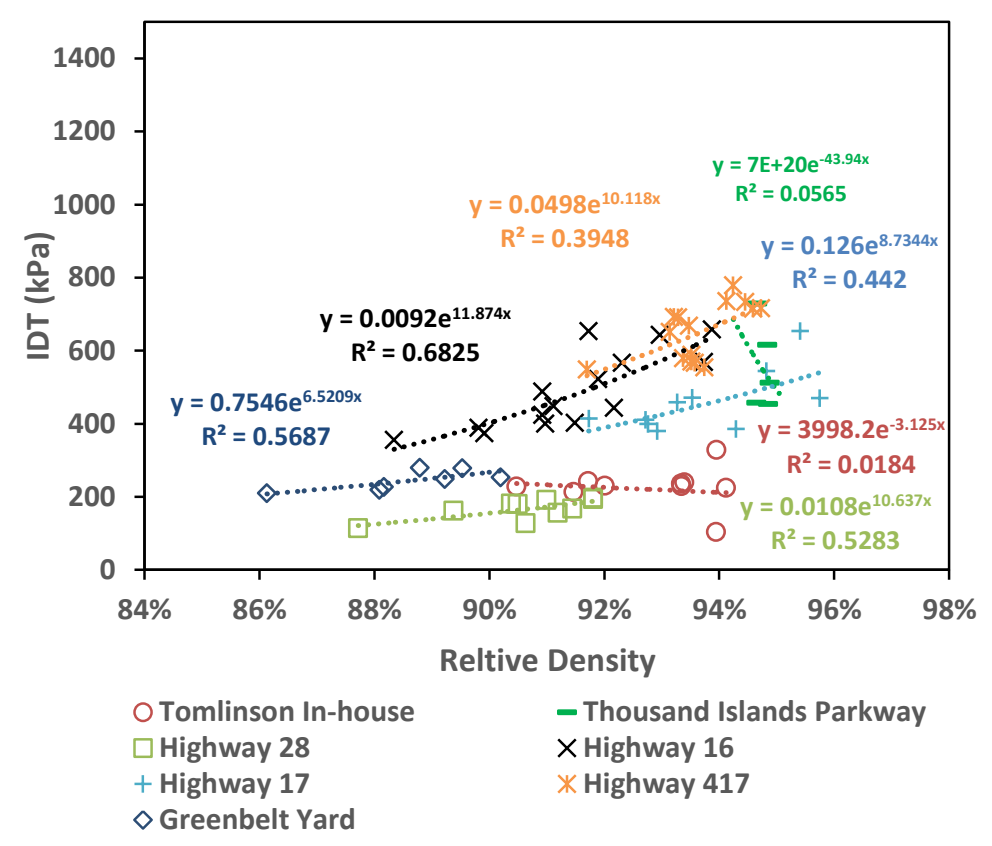


(a)

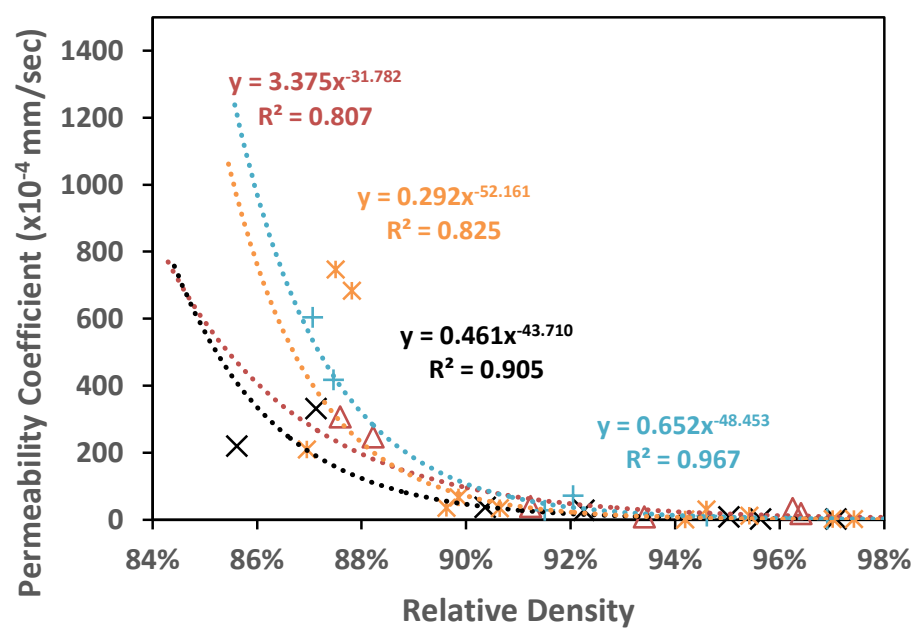

$\triangle$ Highway $15 \times$ Highway 16 + Highway 17 * Highway 417 (b)

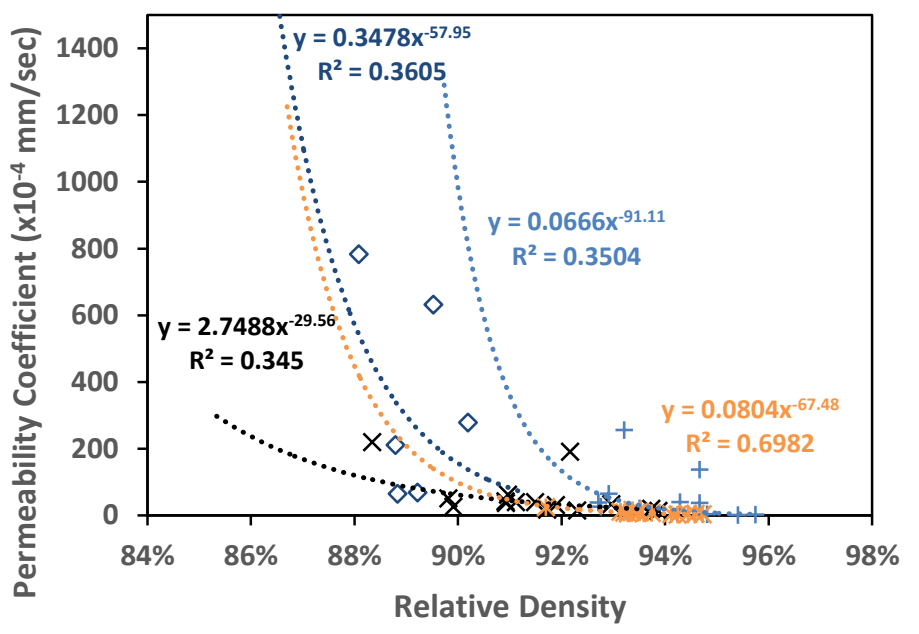

$\times$ Highway 16 + Highway $17 *$ Highway $417 \diamond$ Greenbelt Yard

(c)

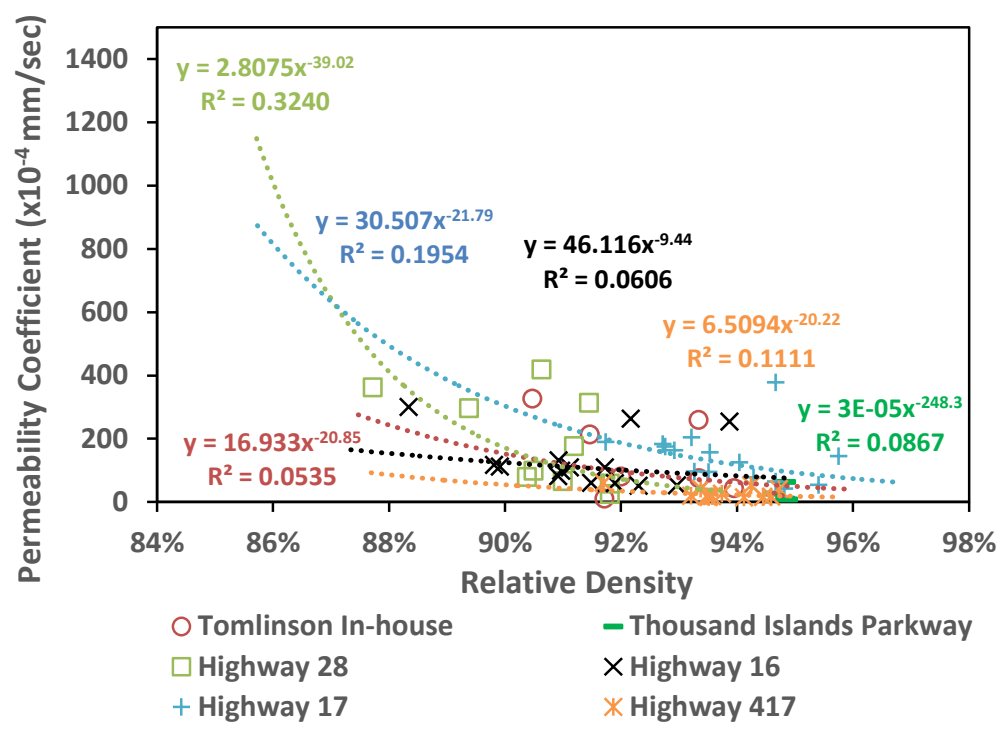


(a)

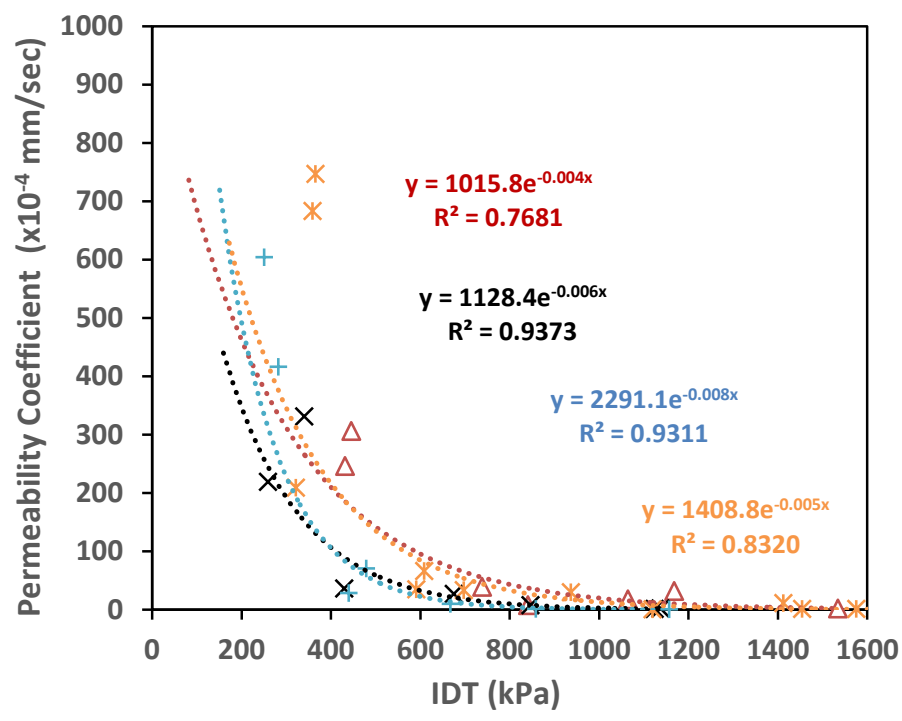

$\triangle$ Highway $15 \times$ Highway 16 + Highway 17 * Highway 417 (b)

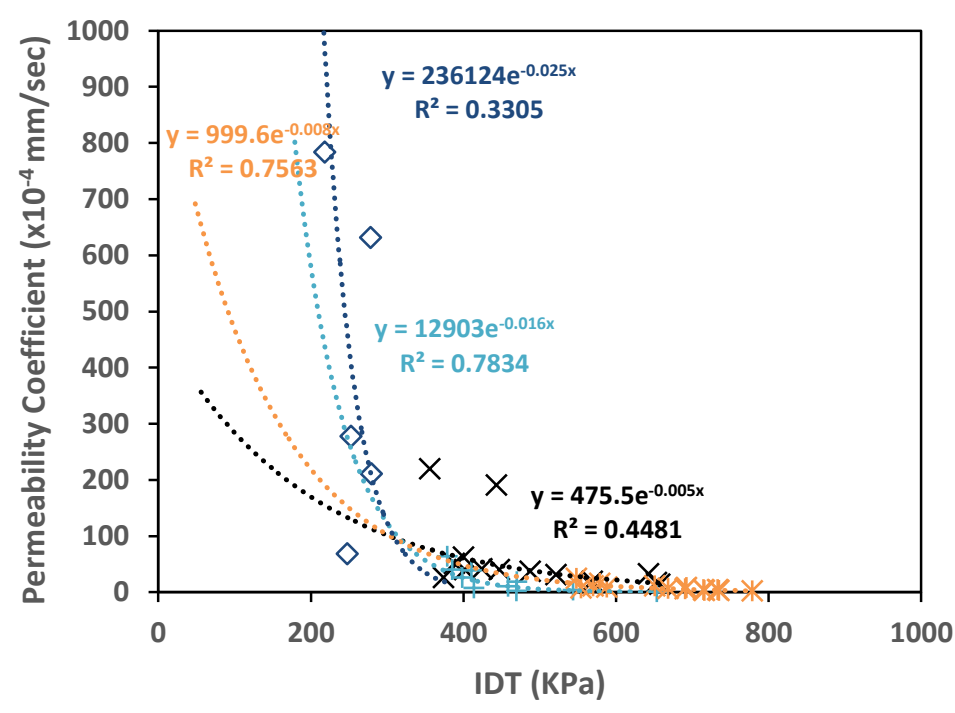

X Highway 16 + Highway $17 *$ Highway $417 \diamond$ Greenbelt Yard

(c)

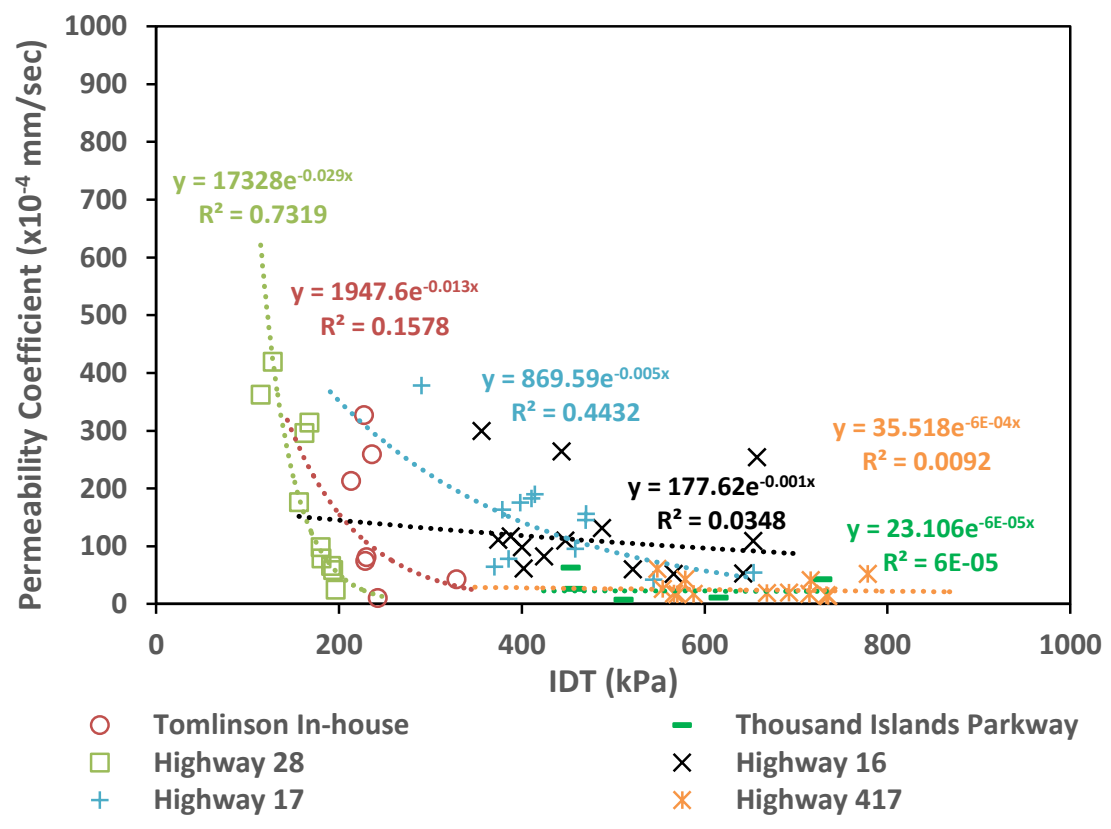




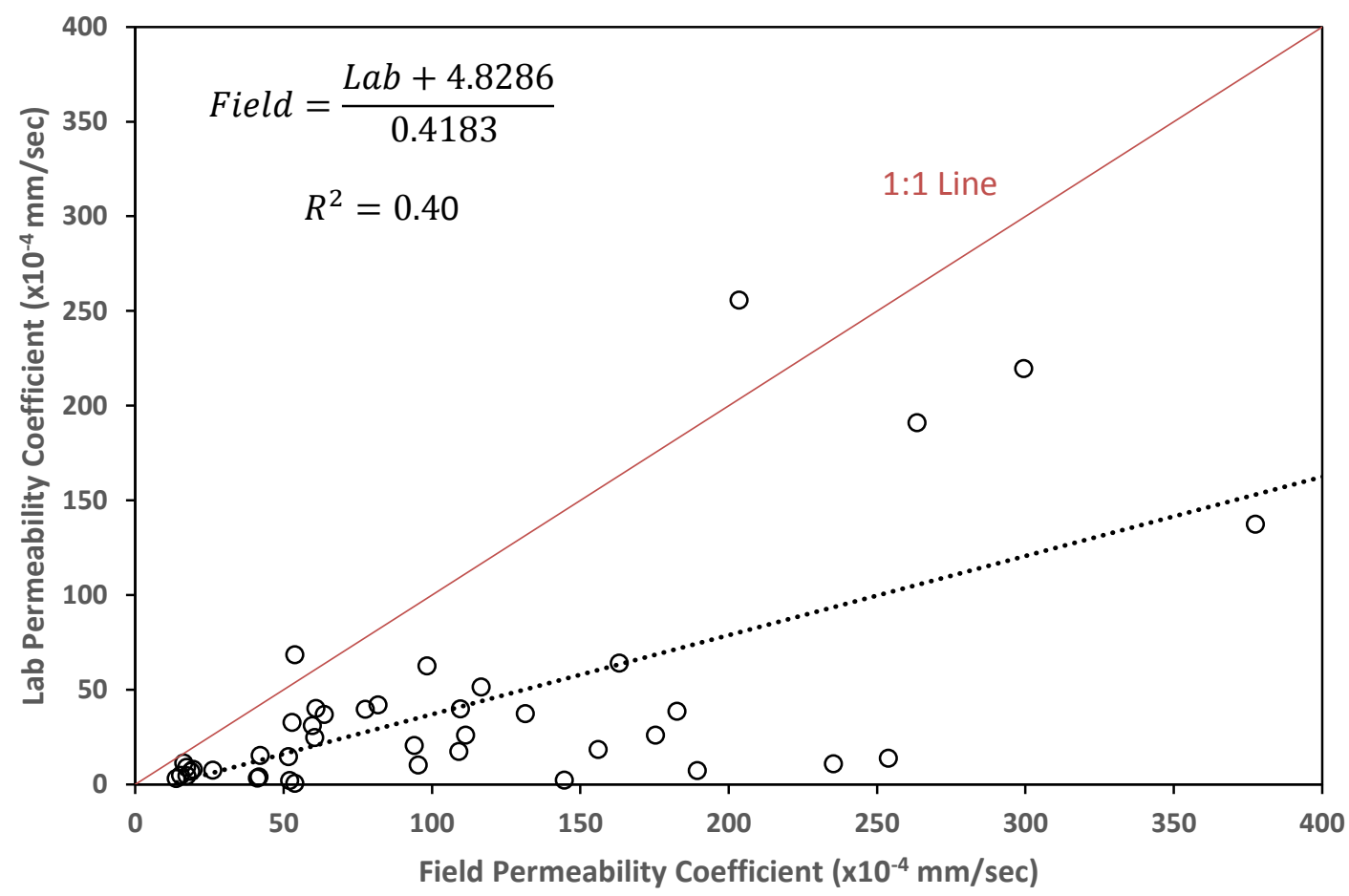

https://mc06.manuscriptcentral.com/cjce-pubs 


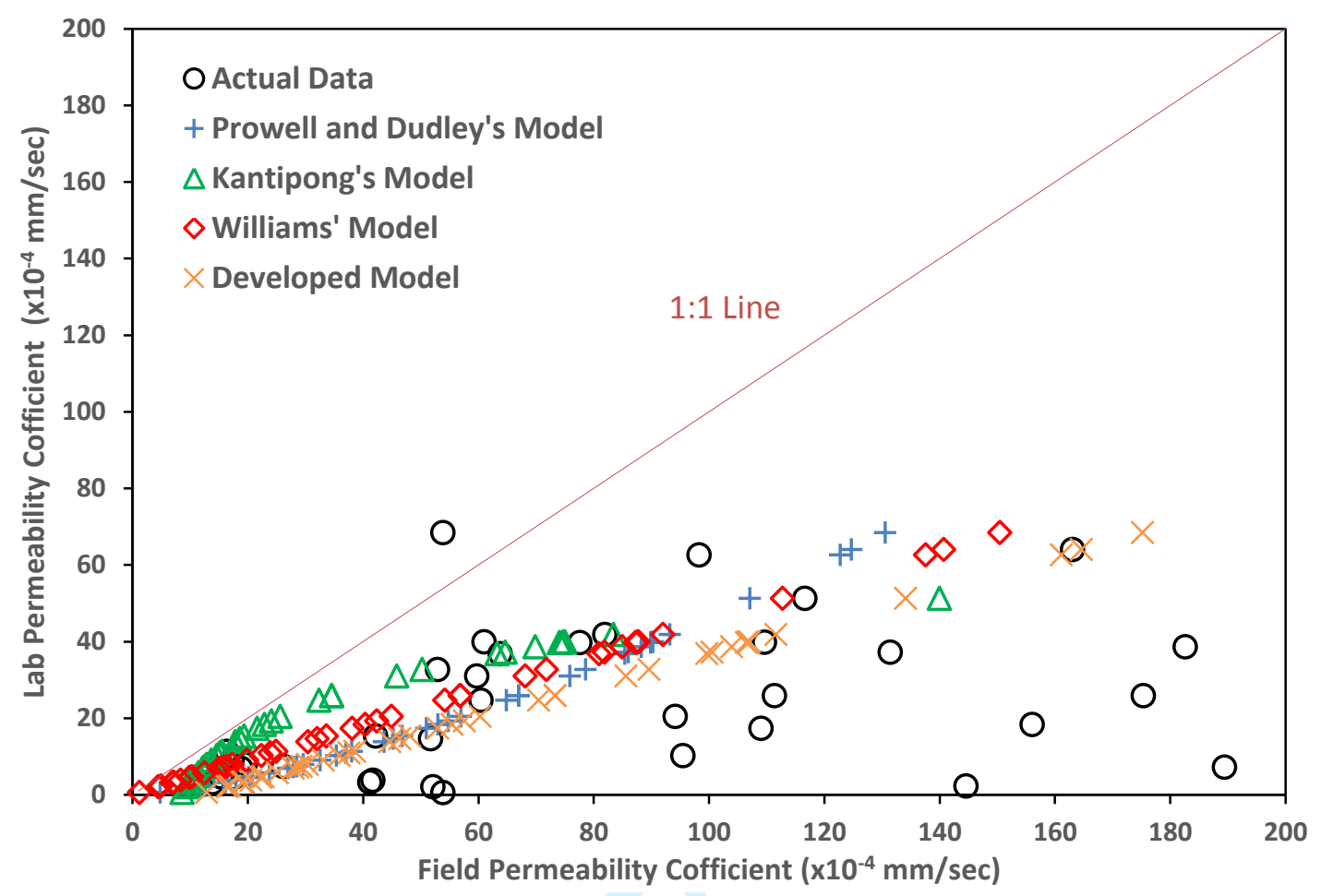

https://mc06.manuscriptcentral.com/cjce-pubs 